\title{
ACINETOBACTER MAIN CAUSE OF HOSPITAL ACQUIRED INFECTIONS: A REVIEW
}

\author{
DINOBANDHU NANDI, ANANIA ARJUNA \\ Department of Medical Laboratory Science School of Physiotherapy and Paramedical Sciences, Lovely Professional University, Phagwara, \\ Punjab, India. Email: anania.arjuna@lpu.co.in
}

Received: 06 February 2017, Revised and Accepted: 21 February 2017

ABSTRACT

Hospital acquired infections (HAIs) are mostly caused by Gram-negative organisms and is one of the major issues in patient safety. These infections are often associated with the medical processes of hospitals such as invasive medical devices and various surgical procedures. Gram-negative organisms account for most infections in the hospital environment because of their ability to acquire resistant against multiple antibiotics. Through different mechanisms including the synthesis of $\beta$ - lactamases, overexpression of transmembrane efflux pump, loss of porins, synthesis of antibiotic modifying enzymes, target mutations, ribosomal mutation or modifications, mutations in lipopolysaccharide structure etc. these organisms have developed drug-resistant property and the genes encoded in plasmids play a vital role in developing the resistant. Among all Gram-negative bacteria, Acinetobacter baumannii is an emerging pathogen that accounts for about $80 \%$ of all reported infections. Although other species of Acinetobacter are also often associated with HAIs. Acinetobacter is non-motile, obligate aerobic Gram-negative coccobacillus and are ubiquitous free-living saprophytes in soil and water. It is commonly transmitted through medical devices such as ventilators, urinary catheters and other invasive devices in hospitals but its ability to colonize on the skin of individuals often increases the rate of transmission through person to person contact. Patients admitted to Intensive Care Unit (ICU) are at the major risk of getting infected by A. baumannii and these includes pneumonia/ventilator associated pneumonia (VAP), bloodstream infections, wound abscesses, urinary tract infections etc.

Keywords: HAI, Acinetobacter baumannii, $\beta$ - lactamases, VAP

(C) 2017 The Authors. Published by Innovare Academic Sciences Pvt Ltd. This is an open access article under the CC BY license (http://creativecommons. org/licenses/by/4. 0/) DOI: http://dx.doi.org/10.22159/ajpcr.2017.v10i5.17511

\section{INTRODUCTION}

Hospital-acquired infection (HAI) also called nosocomial infection is a kind of infection which is acquired in the hospital by a patient in whom the infection was not present at the time of admission but emerged after discharging, and it also includes occupational infections among the staff of the organization [1,2]. Nosocomial infections are mostly caused by Gram-negative organisms and are one of the major issues in patient safety. HAIs are one of the major causes of death [3] which have worldwide prevalence and affect developed, developing, and resource-poor countries. The rate of morbidity and mortality is significantly increased and cause financial losses for health-care system. The study has revealed that within hospital it is mostly prevalent is intensive care units (ICUs) followed by acute surgical and orthopedic wards [4], approximately, 30\% patients in ICU are affected by at least one nosocomial infection [5]. Most frequent causative agents are Pseudomonas aeruginosa, Staphylococcus aureus, Klebsiella pneumoniae and Acinetobacter baumannii (Ab). Over the last 15 years, $\mathrm{Ab}$ has emerged as a potent nosocomial pathogen. It became the second most common Gram-negative bacilli after $P$. aeruginosa to be isolated from clinical specimens, and they rank fourth after ( $P$. aeruginosa, S. aureus, K. pneumoniae) as most frequent hospital-acquired infectious agents. From the last two decades, clinicians worldwide have identified Acinetobacter genus, especially $\mathrm{Ab}$ as a frequent organism associated with critically ill patients [6].

\section{HISTORICAL ANALYSIS OF THE GENUS ACINETOBACTER}

In the early $20^{\text {th }}$ century (1911), a Dutch microbiologist, Beijerinck, isolated an organism from the soil by a culture medium that was enriched by calcium acetate and named it as Micrococcus calcoaceticus [7]. Similar organisms were described and allotted to 15 different genera and species over the following years. In 1954, Brisou and Pre'vot proposed the current taxonomic genus, i.e., Acinetobacter. In Greek, it means non-motile. Brisou and Pre'vot separated the non-motile organisms from those of motile organisms within the genus Achromobacter [8].
However, this was not widely accepted until Baumann et al. concluded that the previously isolated organisms belonged to a single genus for which the name Acinetobacter was proposed. These findings led the genus Acinetobacter for an official acknowledgment in 1971 by the Sub-committee on the Taxonomy of Moraxella and Allied Bacteria. In the 1974 edition of Bergey's Manual of Systematic Bacteriology, the genus Acinetobacter was listed, with the description of a single species, Acinetobacter calcoaceticus [7]. In the "Approved List of Bacterial Names," in contrast, two different species, A. calcoaceticus and Acinetobacter lwoffii, were included, based on the observation that some Acinetobacters were able to acidify glucose whereas others were not [10]. Current taxonomic nomenclature defined as Acinetobacter is within the family Moraxellaceae and order Gammaproteobacteria, which includes the genera Moraxella, Acinetobacter, Psychrobacter, and related organisms [9].

\section{GENERAL DESCRIPTION OF THE GENUS ACINETOBACTER}

They are Gram-negative nonmotile coccobacilli possess very minimum growth requirement. They are strictly aerobe and cannot tolerate anaerobic condition but can survive on a variety of surfaces and aquatic environment. Acinetobacter is non-fermenter but has oxidizing properties. They are catalase positive and oxidase negative organism. DNA contains $39-47 \%$ of $\mathrm{G}+\mathrm{C}$ content. They are a part of the commensal flora of human and animal which are regular contaminants of the hospital environment. Up to $25 \%$ of healthy ambulatory adults exhibit cutaneous colonization by Acinetobacter and are the most common Gram-negative bacteria carried on the skin of hospital personnel [11].

\section{SOURCE AND OCCURRENCE}

They are ubiquitous in nature, and inhabitants of soil, water, and sewage water as well. They are found mostly in aquatic environment. About $97 \%$ of natural water sample has been isolated with Acinetobacter spp. The bacterial count reached up to $100 / \mathrm{ml}$. The organisms have been found to represent $1.0-5.5 \%$ of the HPC flora in drinking-water samples and 
have been isolated from $5 \%$ to $92 \%$ of distribution water samples [12]. In the USA, one survey from untreated ground water has been isolated with the Acinetobacter spp. found in $38 \%$ of water supplies. They are the producer of slime layer, and there are no differences in the slime production of Acinetobacter spp. isolated from water samples and clinical specimens. Acinetobacter spp. are the normal flora of skin and occasionally in the respiratory tract of healthy individuals. Ingestion of drinking water having Acinetobacter spp. do not cause gastrointestinal infections; however, it can cause non-gastrointestinal problems in susceptible patients and individuals associated with health-care settings. Acinetobacter spp. are susceptible to chlorine, so uses of disinfectants can limit the transmission of organism. In an epidemiological survey performed to investigate the colonization of human skin and mucous membranes with Acinetobacter species, up to $43 \%$ of non-hospitalized individuals were found to be colonized with these organisms while in hospitalized patients the carriage rate of Acinetobacter spp. were comparatively high, i.e., 75\% [13]. The fecal carriage rate of Acinetobacter spp. were detected up to $25 \%$ by Dijkshoorn et al. and the predominant species were Acinetobacter johnsonii and Acinetobacter genomic species 11 [15]. Chu et al. found $53 \%$ of medical students and new nurses to be colonized with Acinetobacters in summer versus $32 \%$ in winter [16]. These seasonal variations are associated with the prevalence of Ab infections. Ab was recovered from $22 \%$ of body lice sampled from homeless people [14]. Acinetobacters are capable of surviving on inanimate substances for a longer period. Berlau et al. investigated vegetablesin the United Kingdom and found that 30 of 177 vegetables (17\%) were culture positive for Acinetobacter [17]. Interestingly, $\mathrm{Ab}$ and Acinetobacter genomic species 11 (each at $27 \%$ ) were the predominant species, followed by $A$. calcoaceticus and Acinetobacter genomic species 3 (each at 13\%), while Acinetobacter genomic species 13 was found only once. In Hong Kong, $51 \%$ of local vegetables were culture positive for Acinetobacter species, the majority of which were Acinetobacter genomic species 3 (75\%), but one sample grew $\mathrm{Ab}$ [18]. Houang et al. found Acinetobacters in 22 of 60 soil samples in Hong Kong, and the most frequent species were Acinetobacter genomic species $3(27 \%)$ and $\mathrm{Ab}(23 \%)$, with only one sample yielding A. calcoaceticus [18].

\section{LOAD OF ACINETOBACTER SPP. IN HOSPITAL ENVIRONMENT}

Several studies have shown the prevalence of Acinetobacter spp. in hospital environment but their rate of occurrence vary widely depending on the protective actions and safety measures taken by different hospitals. The presence of Acinetobacter spp. has been found in almost all part of hospital which includes sinks, floors, cupboards, linens, mattresses, ventilators, and respirators. Contamination of mattresses occurs through breaches in plastic covers that allowed water penetration and persistence of the organism in the wet foam of the mattresses. More recently, feather pillows were found to be contaminated with considerable numbers of Acinetobacter in an outbreak of infection in the Netherlands [19]. It suggests that these inanimate things play a major role in transmission of Acinetobacter spp. which contributes them to be a potent nosocomial pathogen. It has been reported that Acinetobacter cells can survive on dry surfaces for durations even longer than that found for $S$. aureus $[20,21]$. An epidemic strain of multi drug resistant (MDR) Acinetobacter spp. has been shown to survive for up to 6 days after inoculation on to dry filter paper, duration similar to that found with $S$. aureus, which persisted for 7 days while $P$. aeruginosa and Escherichia coli survives up to $24 \mathrm{hrs}$ or less [22]. Their ability to survive in all most all inanimate substances and minimal nutritional requirements make them very common nosocomial pathogen associated with outbreaks. The outbreaks also occur when the patient has some underlying disease and various medical processes have implicated, for example, intravenous catheters, respirators, and peritoneal dialysis. [23].

\section{ROUTES OF TRANSMISSION}

Environmental sources and cross-transmissions are the most common cause of transmission of Acinetobacter infections. Possible routes include direct contact, burn and inhalation especially in ICUs where patients are on mechanical ventilation. In patients with Acinetobacter bacteremia, intravenous catheters have also been identified as a source of infection. Water baths and humidifiers are also a potent source of infection. The oral transmission (through ingestion) is not a usual source of infection.

\section{FACTORS CONTRIBUTING TO ESTABLISH A WELL FORMED DISEASE}

Acinetobacter infections are favored by these following factors:

- Ability to upregulate and acquiring resistance gene which enable them to resist mostly all common antibiotics used in health-care setting, and enable them to become MDR bacteria.

- They are part of commensal flora which facilitates the crosstransmission.

- Their nonfastidious property helps them to survive on various inanimate materials as well as in aqueous environment.

- Underlying disorders, for example, long-term diabetes mellitus, immunocompromised state such as in patients with HIV infection can enhance the risk of Acinetobacter infections.

- Drug therapies such as immunosuppressive drugs and antibiotics, chemotherapy, radiotherapy, current surgeries, endotracheal intubation, intravenous procedures, catheterization contribute toward easy development of infection as all mentioned procedures suppress the immunity and make a route for easy entry.

\section{SPECIES OF MEDICAL IMPORTANCE}

Several studies have revealed that among all the different species, $\mathrm{Ab}$ is the most common nosocomial pathogen found in mostly all clinical specimens and are associated with major complications, for example, respiratory tract infections, and septicemia. According to the data of Centers for Disease Control and Prevention, the species Ab accounts for nearly $80 \%$ of reported Acinetobacter infection. Acinetobacter genomic species 3 and 13TU have been implicated in nosocomial outbreaks while A. johnsonii has been associated with catheter-associated bacteremia. A. calcoaceticus- Ab complex $[24,25]$ contains isolates that are mostly glucose acidifying. The majority of glucose-negative, nonhemolytic strains found in clinical specimens seem to be identified mainly as A. Iwoffii, A. johnsonii, Acinetobacter haemolyticus is the species who shows hemolysis. Other groups seem to be implicated only occasionally in human infections.

\section{CLINICAL CASES ASSOCIATED WITH ACINETOBACTER SPP.}

Acinetobacter spp. are associated with various clinical cases which sometimes is often fatal. Their abundant occurrence in nature and minimal nutritional requirement make them a potent pathogen to cause a well-formed infection. They occur mostly in the ICUs, as most of the patients are on ventilation. A mechanical ventilator is a potent source of infection, and it contributes as a source of transmission. Ventilatorassociated pneumonia and ICU-acquired pneumonia are frequent cases occurred in ICUs. Post-surgical abscess and wound infections, bacteremia and septicemia as a result of the surgical and medical process, urinary tract infections on catheterization, pleural effusion, peritonitis, and meningitis are associated with Acinetobacter infections.

\section{HEALTH IMPACT OF ACINETOBACTER INFECTIONS}

MDR strains are associated with critically ill patients. This property to resist approximately all common antibiotics set the mortality rate at a high level, i.e., 26-68\% [26-28]. Acinetobacter infections and colonization are associated with increased mortality [29-31]. Other studies that rigorously controlled for severity of illness did not find Acinetobacter infection to be independently associated with increased mortality [26,32-34]. However, patients with deliberated underlying illness the organism can be responsible for high mortality rate individually. Acinetobacter infection is associated with increased morbidity and a prolonged length of hospital stay. The duration of hospital stay is directly associated with the related infections caused 
by Acinetobacter spp. and MDR- Acinetobacter spp. Patients with Acinetobacter bacteremia had a 5 days excess length of mechanical ventilator dependence and ICU stay, compared with critically ill patients without Acinetobacter infection [33]. The severity of infections is depended on the length of hospital stay and degree of antibioticresistant.

\section{MECHANISM OF ANTI-MICROBIAL RESISTANCE}

Acinetobacter spp. are emerging as a potent threat to hospitalized patients as they are untreatable with the most common antibiotics. The trend to resist the drugs has been extremely enhanced form past two decades. Ab among all species has been developed itself as a most common and also as a super bug associated with nosocomial infections. Upregulation of innate resistance, for example, impermeable outer membrane and acquisition of resistance gene are two major skill used by this bacteria that helps it to become a deadly pathogen in mainly healthcare facility. Their natural habitat is also contributing them to achieve easy transmission of infection. MDR - Ab is very common problem to the physician to treat the patients especially having respiratory problems and associated with ICU units. MDR - Acinetobacter can be defined in two ways, i.e., resistance to carbapenem or resistance to $\geq 3$ classes of antibiotics [35]. Some strains are only treatable with polymyxin, but resistance to them is also been reported in literature. The rapid emergencies of resistant strains of Acinetobacter globally possess the treatment option limited and crucial. In three possible ways, they resist the drugs, i.e., production of enzymes that degrade the antimicrobial substances, mutation that changes the bacterial target sites, and alteration in cellular function, for example, efflux pump [36].

They produce a wide variety of $\beta$-lactamases, enzymes that degrade the $\beta$-lactam ring. This enzyme confers resistance to penicillins, cephalosporins, and carbapenems. They resist broad-spectrum cephalosporins by AmpC cephalosporinase enzyme that is encoded in chromosome $[40,41]$. Class B metallo- $\beta$-lactamases (MBLs) are expressed in certain strains which provide them to resist a wide range of antimicrobial agent including carbapenems [37]. MBLs are easily transferred among bacteria which possess a great chance to get resistant genes easily. Acinetobacter spp. are well known for their resistance capability through alteration in bacterial targets. Porin channels and outer membrane proteins are the way for the drug to reach their targets, alteration in these structures enabling them to be a deadly pathogen that resist all kind of drugs. Loss of proteins from the outer membrane is linked with carbapenem-resistant Ab (CR-Ab) [37]. Various efflux systems are associated with $\mathrm{Ab}$, for example, AdeABC, AdeM, Tet(A), Tet(B). Resistance to colistin is thought to be mediated by changes in the bacterial cell membrane that interfere with the agent's ability to bind bacterial targets [38]. Acinetobacter spp. can acquire genes from Pseudomonas spp. Salmonella spp., etc. A study have shown an interesting fact that in France MDR - Acinetobacter strain consist of a resistance island containing approximately 45 resistant gene and that appeared to have been acquired from species of Pseudomonas, Salmonella, and Escherichia [39]. Another study has been done on $\mathrm{CR}$ property of $\mathrm{Ab}$ and a total of 51 clinically significant $\mathrm{CR}-\mathrm{Ab}$ were isolated from different specimens including tracheal aspirate, blood, wound sample and urine during t 4 months. Modified Hodge's test detected carbapenemase production in 50 out of 51 (98\%) isolates, whereas ethylenediaminetetraacetic acid-disk synergy test detected MBLs production in 48 out of 51 (94.1\%) isolates [42]. These findings support that since last two decades Ab has been emerged as a potent nosocomial pathogen.

\section{MANAGEMENT OF MDR-ACINETOBACTER}

Like all living organisms, microbes face challenges to their own survival as in their environmental and ecological changes. Because of this reason they acquire, develop or evolve mechanisms that favor them to survive in their surroundings. Their short life cycle opens infinite opportunities for genetic mutation to occur. In the other hand, their ability to acquire gene and sharing genes among related and unrelated species facilitate their existence. These properties enable them to respond to environmental as well as ecological changes. Hence, the antibiotic therapy in the health-care system can actually change the ecological atmosphere which can trigger the development of resistant strains. Thus, the uses of antibiotics should be minded and only used at proper dose. Fishman has described some strategies by which these consequences can be controlled which include education, formulary restriction, streamlining, and antibiotic cycling. All of them restrict the unnecessary uses of antibiotics, uses of broad spectrum antibiotics, continuous use of one antibiotic which can limit the occurrence antibiotic resistant strains.

Infectious Diseases Society of America and the Society for Healthcare Epidemiology of America recommend two core strategies for antimicrobial stewardship programs as per 2007 guidelines which says that prospective audit of antimicrobial use with direct interaction and feedback to the prescribing physician and formulation restriction and pre- authorization requirements can lead to significant reductions in antimicrobial use. To manage the load of MDR-Acinetobacter, analysis of susceptibility and antibiogram are at the major concern. Each MDRAcinetobacter isolate must be checked for susceptibility and it should be readily accessible by physicians. They are helpful in both patient care treatments and surveillance of MDR-Acinetobacter.

Antibiogram often deals with the drug pattern of many isolates derived from clinical specimens rather consider for a single isolate. Compilation of drug pattern is generally done by the microbiology laboratory using data from various units. In case of $A b$, susceptibility results from different isolates are compiled during a specific period and must be updated annually. The resulting antibiogram suggests the choice of drug for treatment of Acinetobacter associated infections in that particular unit. They can be used by physician to control the infection when the susceptible result is yet not available for patients. It also used in monitoring the changes of drug susceptibility. In one study, isolate of $\mathrm{Ab}$ obtained from Brahmakumari Hospital was subjected to antibiotic susceptibility testing to get the antibiogram. None of isolates gave the zone of inhibition at all to cefotaxime, they so considered as extended spectrum beta-lactamases. A synergy of cefotaxime and Terminalia chebula has been tested and it has been observed that there was a zone of inhibition formed [43]. This study indicates that the combination of medicinal plant extracts and known antibiotics offers significant potential for the development of novel antimicrobial therapies [43].

\section{REFERENCES}

1. Ducel G, Fabry J, Nicolle L. Guide Pratique Pour la Lute Contre 1' Infection Hospitalière. WHO/BAC/79.1. Geneva: WHO; 2002.

2. Benenson AS. Control of Communicable Diseases Manual. $16^{\text {th }}$ ed. Washington, DC: American Public Health Association; 1995.

3. Ponce de Leon $\mathrm{S}$. The needs of developing countries and the resources required. J Hosp Infect 1991;18:376-81.

4. Ducel G, Fabry J, Nicolle L, editors. Prevention of Hospital-Acquired Infections. A Practical Guide. $2^{\text {nd }}$ ed. WHO/CDS/CSR/EPH/2002.12. Geneva: World Health Organization.

5. Health Care - Associated Infections. World Health Organisation. Available from: http://www.who.int/gpse/country work/gpsc ccisc fact_sheet_en.pdf.

6. Falagas ME, Karveli EA, Siempos II, Vardakas KZ. Acinetobacter infections: A growing threat for critically ill patients. Epidemiol Infect 2008;136(8):1009-19.

7. Beijerinck M. Pigmenten als oxydatieproducten gevormd door bacterien. Ver K Akad Wet Amst 1911;19:1092-103.

8. Brisou J, Prevot AR. Studies on bacterial taxonomy. X. The revision of species under Achromobacter group. Ann Inst Pasteur (Paris) 1954;86(6):722-8.

9. Rossau R, van Landschoot A, Gillis M, de Ley J. Taxonomy of Moraxellaceae fam. nov., a new bacterial family to accommodate the genera Moraxella, Acinetobacter, and Psychrobacter and related organisms. Int J Syst Bacteriol 1991;41:310-9.

10. Skerman VB, McGowan V, Sneath PH. Approved list of bacterial names. Int J Syst Bacteriol 1980;30:225-420.

11. Allen DM, Hartman BJ. Acinetobacter species. In: Mandell GL, 
Bennett JE, Dolin R, editors. Principles and Practice of Infectious Diseases. $5^{\text {th }}$ ed., Vol. 2. Philadelphia: Churchill Livingstone; 2000. p. 2239-44.

12. Bergogne-Berezin E, Towner KJ. Acinetobacter as nosocomial pathogens: Microbiological, clinical and epidemiological features. Clin Microbiol Rev 1996;9:148-65.

13. Seifert H, Dijkshoorn L, Gerner-Smidt P, Pelzer N, Tjernberg I, Vaneechoutte M. Distribution of Acinetobacter species on human skin: Comparison of phenotypic and genotypic identification methods. J Clin Microbiol 1997;35(11):2819-25

14. La Scola B, Raoult D. Acinetobacter baumannii in human body louse. Emerg Infect Dis 2004;10(9):1671-3.

15. Dijkshoorn L, van Aken E, Shunburne L, van der Reijden TJ, Bernards AT, Nemec A, et al. Prevalence of Acinetobacter baumannii and other Acinetobacter spp. in faecal samples from non-hospitalised individuals. Clin Microbiol Infect 2005;11(4):329-32.

16. Chu YW, Leung CM, Houang ET, Ng KC, Leung CB, Leung HY, et al. Skin carriage of Acinetobacters in Hong Kong. J Clin Microbiol 1999;37(9):2962-7.

17. Berlau J, Aucken HM, Houang E, Pitt TL. Isolation of Acinetobacter spp. including A. baumannii from vegetables: Implications for hospitalacquired infections. J Hosp Infect 1999;42:201-4.

18. Houang ET, Chu TW, Leung CM, Chu KY, Berlau J, Ng KC, et al. Epidemiology and infection control implications of Acinetobacter spp. in Hong Kong. J Clin Microbiol 2001;39:228-34

19. Weernink A, Severin WP, Tjernberg I, Dijkshoorn L. Pillows, an unexpected source of Acinetobacter. J Hosp Infect 1995;29(3):189-99.

20. Nagler A, Pavel L, Naparstek E, Muggia-Sullam M, Slavin S. Typhlitis occurring in autologous bone marrow transplantation. Bone Marrow Transplant 1992;9(1):63-4.

21. Getchell-White SI, Donowitz LG, Gröschel DH. The inanimate environment of an intensive care unit as a potential source of nosocomial bacteria: Evidence for long survival of Acinetobacter calcoaceticus. Infect Control Hosp Epidemiol 1989;10(9):402-7.

22. Allen KD, Green HT. Hospital outbreak of multi-resistant Acinetobacter anitratus: An airborne mode of spread? J Hosp Infect 1987;9(2):110-9.

23. Abrutyn E, Goodhart GL, Roos K, Anderson R, Buxton A. Acinetobacter calcoaceticus outbreak associated with peritoneal dialysis. Am J Epidemiol 1978;107(4):328-35.

24. Gerner-Smidt P, Tjernberg I, Ursing J. Reliability of phenotypic tests for identification of Acinetobacter species. J Clin Microbiol 1991;29(2):277-82.

25. Kämpfer P, Tjernberg I, Ursing J. Numerical classification and identification of Acinetobacter genomic species. J Appl Bacteriol 1993;75(5):259-68.

26. Sunenshine RH, Wright MO, Maragakis LL, Harris AD, Song X, Hebden $\mathrm{J}$, et al. Multidrug-resistant Acinetobacter infection mortality rate and length of hospitalization. Emerg Infect Dis 2007;13(1):97-103.

27. Seifert H, Strate A, Pulverer G. Nosocomial bacteremia due to Acinetobacter baumannii. Clinical features, epidemiology, and predictors of mortality. Medicine (Baltimore) 1995;74(6):340-9.
28. Kwon KT, Oh WS, Song JH, Chang HH, Jung SI, Kim SW, et al. Impact of imipenem resistance on mortality in patients with Acinetobacter bacteraemia. J Antimicrob Chemother 2007;59(3):525-30.

29. Falagas ME, Kopterides P, Siempos II. Attributable mortality of Acinetobacter baumannii infection among critically ill patients. Clin Infect Dis 2006;43(3):389.

30. Lee NY, Lee HC, Ko NY, Chang CM, Shih HI, Wu CJ, et al. Clinical and economic impact of multidrug resistance in nosocomial Acinetobacter baumannii bacteremia. Infect Control Hosp Epidemiol 2007;28(6):713-9.

31. Abbo A, Carmeli Y, Navon-Venezia S, Siegman-Igra Y, Schwaber MJ. Impact of multi-drug-resistant Acinetobacter baumannii on clinical outcomes. Eur J Clin Microbiol Infect Dis 2007;26(11):793-800.

32. Albrecht MC, Griffith ME, Murray CK, Chung KK, Horvath EE, Ward JA, et al. Impact of Acinetobacter infection on the mortality of burn patients. J Am Coll Surg 2006;203(4):546-50.

33. Blot S, Vandewoude K, Colardyn F. Nosocomial bacteremia involving Acinetobacter baumannii in critically ill patients: A matched cohort study. Intensive Care Med 2003;29(3):471-5.

34. Fournier PE, Richet H. The epidemiology and control of Acinetobacter baumannii in health care facilities. Clin Infect Dis 2006;42(5):692-9.

35. Falagas ME, Koletsi PK, Bliziotis IA. The diversity of definitions of multidrug-resistant (MDR) and pandrug-resistant (PDR) Acinetobacter baumannii and Pseudomonas aeruginosa. J Med Microbiol 2006;55:1619-29.

36. Bonomo RA, Szabo D. Mechanisms of multidrug resistance in Acinetobacter species and Pseudomonas aeruginosa. Clin Infect Dis 2006;43 Suppl 2:S49-56.

37. Thomson JM, Bonomo RA. The threat of antibiotic resistance in Gram-negative pathogenic bacteria: Beta-lactams in peril! Curr Opin Microbiol 2005;8(5):518-24.

38. Li J, Nation RL, Milne RW, Turnidge JD, Coulthard K. Evaluation of colistin as an agent against multi-resistant Gram-negative bacteria. Int J Antimicrob Agents 2005;25(1):11-25.

39. Fournier PE, Vallenet D, Barbe V, Audic S, Ogata H, Poirel L, et al. Comparative genomics of multidrug resistance in Acinetobacter baumannii. PLoS Genet 2006;2(1):e7.

40. Gales AC, Pfaller MA, Sader HS, Hollis RJ, Jones RN. Genotypic characterization of carbapenem-nonsusceptible Acinetobacter spp. isolated in Latin America. Microb Drug Resist 2004;10(4):286-91.

41. Davis KA, Moran KA, McAllister CK, Gray PJ. Multidrug-resistant Acinetobacter extremity infections in soldiers. Emerg Infect Dis 2005;11(8):1218-24.

42. Pooja BM, Sweta RS, Sheela DK, Dileep VK. Characterization of carbapenem resistant Acinetobacter baumannii isolated in a tertiary care hospital: Epidemiology and treatment outcome. Int J Pharm Pharm Sci 2016;8(7):277-81

43. Rabadia A, Kamat SD, Kamat DV. Study of synergistic action of cefotaxime and Terminalia chebula on Acinetobacter baumannii using checkerboard assay. Int J Pharm Pharm Sci 2013;5(3):830-2. 